\title{
UMA EXPERIÊNCIA POÉTICA NO PROJETO LEITURA CLANDESTINA: INTERPRETAÇÕES DE CLARICE EM CORPOS, VOZES E PAPÉIS
}

\author{
PLOIA, T. H.1; TORRES, A. S²; FRONCKOWIAK, A. C. ${ }^{3-}$.
}

PALAVRAS-CHAVE: Clarice Lispector; Leitura, literatura e ensino; Extensão universitária em Letras; Experiência poética

\section{RESUMO}

Este artigo pretende divulgar o projeto de extensão Leitura Clandestina, idealizado por acadêmicos de Letras na intenção de homenagear, em 2020, o centenário de Clarice Lispector, escritora brasileira que transformou o cenário literário de sua época. No texto, discorremos acerca de razões que impulsionaram a proposta e sua consecução: a) o desafio que a pandemia trouxe ao exercício da docência, tanto para os professores quanto para os licenciandos; e b) a percepção de que muitos professores de Literatura e Língua Portuguesa consideram os textos da escritora complexos e não os apresentam aos alunos. A iniciativa buscou aproximar crianças e jovens da obra clariceana, favorecendo a oportunidade de exercerem a leitura, aprimorando suas habilidades técnicas e desfrutando da sua realização enquanto ação poética, que os mobilizasse a vivenciar textos da autora, selecionados pela curadoria do Leitura Clandestina, que levou em conta temáticas relativas ao universo humano comum a adultos e jovens, presentes na sua obra. Esse objetivo foi delineado a partir da parceria com admiradores da obra clariceana, leitores que se integraram ao intento e elaboraram uma produção interpretativa de seus textos, por desejo pessoal ou incentivados por seus professores, no caso de estudantes das escolas. Assim, argumentamos a relevância da curricularização de projetos de extensão acadêmica, espaço em que se concretizam processos vinculados à pesquisa e que produz experiências que têm sentido para os usuários e para aqueles que as estão produzindo, como aconteceu com o grupo. Em relação à leitura, o artigo revela que iniciativas que favorecem os papeis ativos dos leitores, traduzindo em diferentes dimensões da linguagem suas impressões e interpretações, validam o protagonismo leitor dos participantes. A proposta culminou em publicações no Instagram, onde buscamos agir enquanto mediadores de leitura, despertando a curiosidade e o interesse da audiência em aprender mais sobre Clarice Lispector, sua vida, suas obras literárias, além de mostrar outras de suas inclinações artísticas com a exibição de suas pinturas.

\section{A POETIC EXPERIENCE IN THE LEITURA CLANDESTINA PROJECT: INTERPRETATIONS OF CLARICE IN BODIES, VOICES AND PAPERS}

\begin{abstract}
KEYWORDS: Clarice Lispector; Reading and literature teaching; University extension in Languages; Poetic
\end{abstract} experience

\begin{abstract}
This article aims to disseminate the extension project Leitura Clandestina, idealized by academics of Literature to honor, in 2020, the centenary of Clarice Lispector, Brazilian writer who transformed the literary scene of her time. In the text, we discuss the reasons that drove the proposal and its achievement: a) the challenge that the pandemic brought to the exercise of teaching, both for teachers and undergraduates; and b) the perception that many teachers of Literature and Portuguese Language consider the writer's texts complex and do not present them to students. The initiative sought to bring children and young people closer to the work of Clarice, providing them with the opportunity to practice reading, improving their technical skills and enjoying its realization as a poetic action that would mobilize them to experience texts by the author, selected by the curators of Leitura Clandestina, which took into account themes related to the human universe common to adults and young people, present in her work. This objective was outlined based on the partnership with admirers of Clarice's work, readers who joined the project and elaborated an interpretative production of her texts, by personal desire or encouraged by their teachers, in the case of school students. Therefore, we argue the relevance of curricularization of academic extension projects, space in which processes linked to research are materialized and that produces experiences that have meaning for users and for those who are producing them, as has happened with the group. Regarding reading, the article reveals that initiatives that favor the active roles of readers, translating their impressions and interpretations into different dimensions of language, validate the protagonism reader of the participants. The proposal culminated in publications on Instagram, where we sought to act as reading mediators, arousing the curiosity and interest of the audience in learning more about Clarice Lispector, her life, her literary works, as well as showing other of her artistic inclinations with the exhibition of her paintings.
\end{abstract}

\footnotetext{
${ }^{1}$ Acadêmica do curso de Licenciatura em Letras - Português/Inglês na Universidade de Santa Cruz do Sul.

2 Acadêmica do curso de Licenciatura em Letras - Português/Inglês na Universidade de Santa Cruz do Sul..

${ }^{3}$ Doutora em Educação, Universidade Federal do Rio Grande do Sul (UFRGS), RS - Brasil e docente do Departamento de Ciências,

Humanidades e Educação, Universidade de Santa Cruz do Sul (UNISC) acf@unisc.br
} 


\section{INTRODUÇÃO}

No âmbito escolar, muitas vezes, a leitura literária ainda é uma ação desempenhada com resistência por parte dos alunos. Embora não possamos afirmar com certeza os motivos, alguns fatores relacionados à mediação leitora já têm sido referidos por inúmeros pesquisadores e são confirmados na experiência da docência. Um deles se liga à maneira como o ato de ler é compreendido, frequentemente vinculado à passividade do corpo que levaria à concentração da mente para maior fruição, o que nem sempre se confirma nas salas de aulas.

A leitura não é um conceito estanque e abstrato. Há muitos modos de ler e eles são impulsionados pela infinidade de gêneros que não cessam de surgir, exigindo habilidade leitora e, principalmente, flexibilidade intelectual de professores para perceberem as implicações da forma na apreensão do conteúdo. Por vezes, a falta de preparo e de condições para a formação continuada leva docentes a não instigarem o alunado a reconhecer o caráter imprescindível e inquestionável da leitura, já que lemos a todo o momento. E isso impacta de modo desfavorável a leitura dos textos literários propostos, atividade essencial para a construção de significados e relações no e com o mundo, cuja prática acaba sendo concebida enquanto mera oportunidade para exercer um julgamento decisório impressionista entre gostar ou não. Contudo, ler não depende de um julgamento, mas de uma ação deliberada para a qual podemos ser conquistados.

A pesquisadora e professora argentina Cecília Bajour (2012) sustenta que os livros lidos na infância e adolescência geram um impacto no leitor, nem sempre positivo. De fato, grande número de estudantes deixa a leitura literária de lado devido a experiências desfavoráveis com obras apresentadas de modo gratuito, irrelevante e distanciadas de contextualização. Qual é o caminho, então, que o professor pode percorrer para mudar esse cenário, levando em consideração a obrigatoriedade de ler certas obras na escola? Ou melhor, como engajar estudantes na leitura dessas obras? Discorremos sobre o assunto a partir do contexto do projeto Leitura Clandestina, motivando a reflexão sobre soluções que nos parecem possíveis.

Criado pelos alunos Andressa dos Santos Torres, Cássio Souza da Silveira, Daniela Machado de Oliveira, Maria Cristina Michel Heffel, Sara Silveira Franco e Talita Hoelz Ploia do Curso de Letras - Português/Inglês da Universidade de Santa Cruz do Sul (UNISC), o projeto atendeu uma proposta de curricularização da extensão, na disciplina Diálogo Educacional Comunitário: Leitura de Diferentes Gêneros e Linguagens, integrante dos currículos de licenciaturas e ministrada pela professora Ângela Cogo Fronckowiak, em 2020. Grupos de estudantes, reunidos por afinidades, deram início a consecução de projetos diferenciados, o Leitura Clandestina: Interpretações de Clarice em Corpos, Vozes e Papéis, que teve como objetivo principal homenagear a obra de Clarice Lispector, visto que em 2020 foi celebrado seu centenário. Este objetivo principal se desdobrou em outros secundários; dentre eles, destacam-se a recepção dos textos da autora em um período de pandemia e a desmistificação de que a produção literária clariceana é de difícil compreensão e, por esse motivo, deve permanecer fora da escola. Os resultados provaram, como esperávamos, que o entendimento da dificuldade da leitura pode ser desfeito e que há outros modos de aproximar os estudantes da literatura. A iniciativa possibilitou, assim, ajudar crianças e adolescentes que estão na educação básica a terem um contato, talvez o primeiro, com a obra de Lispector.

Como nos pede a BNCC, o projeto alicerçou-se na Área de Linguagem e suas Tecnologias (LGG), nos vínculos que ela ressalta entre educação, cultura e comunicação, através da consolidação das habilidades de uso e 
reflexão sobre as linguagens artísticas, corporais e verbais, buscando a participação de diversas áreas, ampliando a capacidade de expressão e vinculando-se aos Parâmetros Curriculares Nacionais, que exploram oralidade, leitura, escuta, produção de textos e análise linguística/semiótica. Essa compreensão sobre diferentes formas de linguagens e práticas culturais utilizando a arte, corpo e voz possibilita a mobilização desses conhecimentos na recepção e produção de discursos nos diferentes campos de atuação social e nas diversas mídias, ampliando a forma de participação na sociedade, o entendimento e as possibilidades de interpretação crítica da realidade, outras perspectivas e explicações.

A pandemia não foi um empecilho para a realização e concretização dos objetivos do Leitura Clandestina, pois nossa proposta extensionista buscou proporcionar encontros, neste período de necessário distanciamento social, com aquilo que salva nossa alma, que nos faz vibrar e nos mantém vivos: a arte. Sobre o momento caótico em que vivemos, Ana Elisa Ribeiro (2020) nos diz que,

\footnotetext{
sabemos todos e todas que vivemos algo de inesperado e diferente. Se, de um lado, isso nos igualou, no susto coletivo e no não saber como lidar (sequer os/as cientistas sabiam), também nos diferenciou na capacidade e na condição - social, econômica - de encontrar soluções para a sobrevivência e para evitar o caos e a barbárie. (p. 145)
}

Nosso projeto foi, então, uma resposta à barbárie, pois através do contato com textos e obras de Lispector, cuja curadoria inicial, como veremos, foi por nós realizada, incentivamos professores, alunos e público interessado a um olhar diferenciado sobre o existir e quisemos que esses encontrassem, na literatura, o indizível. Em nossa concepção, associa-se à missão de (futuros) professores apontar meios de ressignificar a vida e sugerir reflexões filosóficas acerca do que sentimos, além de estar junto quando se precisa de auxílio para transbordar o que nos preenche e sufoca, ou, também, ouvir, acalmar, acolher, saber contemplar o silêncio de quem busca suas respostas ainda não encontradas. Faz parte da nossa vocação fazermos da nossa existência um meio de transformar algo difícil em algo possível, viabilizando a ação poética dos sentimentos e sensações humanas.

Tendo como marco de início o mês de março de 2020, o projeto, que ocorreu em um perfil na plataforma da rede social Instagram, ainda está em andamento, contemplando cada uma das produções recebidas de alunos, professores e convidados.

\section{FUNDAMENTAÇÃO TEÓRICA}

Clarice Lispector concedeu uma entrevista à TV Cultura, no programa Panorama, em 1977, que serviu-nos de motivação. A fala da autora no programa é a base da construção e do desenvolvimento deste projeto. Durante a conversa com Júlio Lerner, a escritora contou que tinha uma proximidade muito grande com estudantes, chegando a recebê-los em casa. Lispector comentou algo curioso: pessoas formadas, ou seja, professores, consideravam sua obra um objeto de difícil interpretação; os estudantes, pelo contrário, liam e reliam seus livros. Para os idealizadores do Leitura Clandestina, o comentário da autora sobre os professores se mantém atual: há uma certa resistência em apresentar textos clariceanos na escola, mesmo no Ensino Médio. Assim, do desejo de transformar, ainda que em uma escala pequeníssima, a experiência leitora do alunado e a visão docente sobre os textos de Clarice Lispector, veio ao mundo Leitura Clandestina, vontade que iniciou a partir das trocas literárias entre os integrantes do grupo. 
$\mathrm{O}$ ato de questionar o modo como a literatura é abordada nas salas de aula e quais impactos produz foi essencial no processo de reflexão crítica sobre o projeto e, passados quase doze meses, respostas definitivas ainda não foram elaboradas. Nesse sentido, Maria Aparecida Vigginani Bicudo (2005), pesquisadora e docente brasileira, defende que pesquisar significa ter uma interrogação e segui-la, não somente em uma direção, mas em todas as que forem aparecendo no caminho, buscando, assim, as várias dimensões da pergunta inicial. Nas primeiras resoluções sobre Leitura Clandestina, isso apareceu de forma nítida quando os integrantes do grupo se propuseram a pensar quais seriam os tipos de produção que os estudantes poderiam criar. A preocupação em acolher, com ternura, a subjetividade de cada participante levou-nos à certeza de que não haveria uma imposição no que diz respeito a criatividades individuais ou coletivas, pois seria prejudicial ao estudante o sentir a necessidade de adaptar sua interpretação a um determinado tipo de linguagem. A intensidade da pergunta inicial confirma que a oportunidade que estaríamos ofertando aos jovens, crianças e professores interessaria, pois os desacomodariam, de forma similar ao que vem acontecendo com os integrantes do grupo, pela prática e experiência em leitura e em situações escolares, propiciadas pela graduação em Letras.

0 projeto Leitura Clandestina foi gestado na dimensão da extensão acadêmica, espaço onde se manifesta a concretude viva daquilo que se pesquisa, ou melhor, a extensão é a concretização de um processo sempre inacabado de pesquisa e formação. Com ela é possível colocar em prática experiências que têm sentido, não só para os usuários, mas também para aqueles que as estão produzindo. Bicudo (2005) discute sobre a noção do rigor na pesquisa, dizendo que não significa somente exatidão, mas sim atenção aos procedimentos que a envolvem, buscando entender com clareza o que move o ato de pesquisar. Dessa forma, podemos pensar as salas de aula como espaços onde o olhar do docente está voltado para os impactos do ato de ensinar, que é também pesquisa, afinal, na docência procuramos entender o ser humano e como se dá o seu processo de aprendizagem e de significação do e no mundo. Na medida em que as experiências não são oriundas apenas da aplicação dos saberes teóricos através de uma prática, tais saberes exteriorizam a intuição, tão necessária numa área formativa como a docência, em que a noção de ciência exibe necessariamente sua contraparte prática. Fazer ciência, em cursos de formação para o magistério, significa não só aprender uma técnica, mas ter a coragem de entender que, quando se trata de gente, teremos de sempre continuar perguntando e refazendo a pergunta a cada vez que a formularmos diante de uma sempre nova outra pessoa.

A formação em uma licenciatura, constantemente, nos remete à reflexão acerca do exercício do aprender. Na universidade, enquanto alunos, compreendemos que as experiências vividas na escola têm papel fundamental na nossa constituição, tanto em termos do aprofundamento de nosso pensamento crítico e reflexivo, quanto na validação de nossa sensibilidade. Os anos transcorridos no espaço escolar não são mera etapa de nosso desenvolvimento cognitivo, mas condicionantes para a qualidade de cidadania que poderemos viabilizar a nós e àqueles que conosco conviverem. A leitura permeia todo o ciclo de formação na educação básica, contudo, com raras exceções, seu ordenamento funcional e utilitário acaba determinando uma execução aquém de sua disposição à reflexão e ao refúgio íntimos. Nem sempre, durante os 12 anos escolares, esta é uma experiência possível, pois o modo como se dá a escolarização da leitura, principalmente a literária, dificulta a construção do letramento literário. Diante desse cenário, o projeto aqui descrito foi impulsionado por indagações concernentes a esse tema: por que há estudantes que apreciam ler e outros não, ainda que frequentem a mesma escola? Será que há, de fato, estudantes que desapreciam os livros? 
Jorge Larrosa Bondía (2002) discorre sobre a dificuldade crescente de que a experiência seja vivenciada, tornando-se rara pela falta de tempo. Cada vez mais se tem pressa, reduzindo o estímulo fugaz e instantâneo, imediatamente substituído por outro estímulo ou por outra excitação igualmente fugaz e efêmera. A obsessão pela novidade, a velocidade dos acontecimentos e a vivência instantânea, pontual e fragmentada, nos impedem de conectar de forma significativa os acontecimentos. E é tendo isso como referência que propomos uma pausa na correria e na velocidade com que passamos os olhos pelas telas e pelos livros em leituras dinâmicas para nos focar nas linhas elaboradas de Clarice Lispector.

Dentro do ambiente acadêmico da graduação, é maior o contato com realidades vivenciadas por outros corpos, localidades e classes sociais, que são determinantes no que diz respeito ao acesso à educação e à presença contínua da cultura na vida desses sujeitos. A partir disso, há a percepção de que, na nossa trajetória leitora na escola, muitas lacunas não foram preenchidas devido ao emprego de uma didática muito voltada à imposições literárias e memorização de informações, e pouco preocupada com o contexto das obras e a fruição do texto. Como diz Larrosa, "nunca se passaram tantas coisas, mas a experiência é cada vez mais rara" (2002, p.21), argumentando que a sociedade da informação na qual vivemos dificulta que algo nos aconteça, pois hoje tudo demanda rapidez e não há tempo para contemplação, introspecção e reflexão sobre nós mesmos e nem sobre o que nos rodeia. As escolas são espaços que poderiam proporcionar experiências literárias significativas para os estudantes, ou seja, que conversem, de forma direta, com os anseios dos leitores; no entanto, vemos o que Larrosa critica: pouco tempo para apreciação do texto literário, resultando em alunos desinteressados nas leituras propostas pelo professor, o que constrói uma significação negativa do que é literatura. A academia nos proporciona uma contra ação a essa lógica pouco atrativa, e nos oferta formas diferentes de construir experiências a partir da literatura, que seriam de muita valia se fossem inseridas na realidade pedagógica dos estudantes, pensando o contexto no qual os sujeitos se encontram. Ao colocarmo-nos diante da prática pedagógica, as perguntas que vão surgindo juntamente com as inquietações não conseguem ficar no plano abstrato. Quanto mais estudamos, lemos e perguntamos, mais queremos saber de que maneira podemos ser a diferença nos espaços onde há formação de seres humanos.

Como mencionado no início desta fundamentação, ainda há docentes que optam por deixar as obras de Clarice Lispector fora das discussões literárias. Nesse sentido, a universidade, num movimento contrário, nos propõe reflexões sobre a leitura na escola, para que nós, enquanto docentes, possamos fazer diferente, buscando outros resultados. A resistência à inserção de obras clariceanas em sala de aula pode ter sua raiz na crença mais ou menos popular de que os brasileiros não leem, logo adolescentes não leem e não têm capacidade para interpretar textos como os de Clarice Lispector. Ora, os jovens leem, porém talvez não leiam o que é proposto pelo professor. Talvez algumas indicações possam criar desinteresse nos estudantes devido à falta de contextualização e pela forma como são sugeridas as abordagens, dificultando a compreensão da intencionalidade da obra, do autor e do professor; assim como o adulto, os adolescentes têm prazer em ler textos significativos para suas vidas, fato que talvez passe despercebido para muitos educadores. 0 docente em Literatura, ao escolher as obras que acompanharão os estudantes durante o ano letivo, frequentemente escolhe textos que por ele são queridos e dialogam com sua identidade; no entanto, a partir desse recorte, onde os interesses literários do alunado tornam-se importantes durante a seleção literária? 
Segundo a pesquisadora brasileira Magda Soares (2011), esse entendimento de que determinados textos são inapropriados para crianças e adolescentes, seja pela forma ou pelo conteúdo, advém de uma perspectiva escolarizada de compreender a literatura. A escolarização de textos literários toma para si os livros, analisando se há como encaixá-los em um plano escolar; assim, a literatura deixa de ser fruição para se tornar um instrumento pedagógico, devido a crença de que certos livros têm destinatário explícito: são destinados à infância ou ao público jovem. A opinião popular sobre a obra de Clarice Lispector advém de uma concepção já escolarizada da leitura literária, pois declaram que a ficção de Lispector não é de fácil compreensão e, por esse motivo, os estudantes em idade escolar irão depreciá-la. Nota-se que há uma ausência de análises de conteúdo dos livros escritos por Clarice, pois olhando-os mais de perto percebe-se que não há inadequação para nenhuma idade; a fala da autora, citada acima, é prova de que jovens possuem capacidade leitora e interpretativa para ler Lispector, e muitos deles tornam-se apreciadores da obra. Soares problematiza o conceito de escolarização da literatura citando Drummond, que já havia iniciado esse questionamento nos anos 40. Para o autor mineiro, o termo "literatura infantojuvenil" é duvidoso; ele entende que não existem narrativas para determinadas idades e pergunta se seria a criança "um ser à parte, estranho ao homem, e reclamando uma literatura também à parte? Ou será a literatura infantil algo de mutilado, de reduzido, de desvitalizado - porque coisa primária, fabricada na persuasão de que a imitação da infância é a própria infância?" (1944, apud SOARES, 2011). Assim, reduzem-se os anos iniciais da vida a uma desvitalização, tomando como pressuposto uma incapacidade de compreensão por parte de quem compõe esse grupo.

A partir dos fundamentos teóricos abordados acima, Leitura Clandestina visou proporcionar uma outra inserção da literatura na vida dos estudantes, através da desmistificação dos limites imaginários impostos aos textos de Clarice Lispector. 0 projeto planejou dar aos alunos a ocasião para agirem através da leitura, experimentando uma vivência poética por meio de crônicas, contos e demais obras da autora. Adentrando os textos e vivenciando as narrativas, compreendendo um pouco mais sobre o humano e as paixões que nos transpassam, quem sabe eles pudessem passar a ver o cotidiano com mais calma, a fim de serem transformados pelo instante, como faz Clarice, ao fazer uso da palavra e colocá-la no papel de maneira tão densa que se assemelha às nossas vidas.

A leitura é uma tarefa que demanda comprometimento por parte do leitor, é diferente de rolar o feed do Instagram ou do Facebook e conseguir informações em poucos segundos. 0 processo de decodificação envolve atenção ao texto, tecendo relações entre as palavras ali postas, mas para compreender se vai muito além disso. A interpretação não é somente uma atividade cognitiva, a cognição é insuficiente para formar leitores ativos: é processo de paixão, envolvendo sentimentos, bagagens e criando conexão entre o que está escrito e o que trazemos no nosso íntimo. Apaixonar-se por enredos, personagens, lugares e a própria linguagem é tão essencial quanto a cognição, se não mais, pois quem persevera na leitura de textos insatisfatórios? Há uns poucos que sim, pela necessidade de obter informações; porém, se existe a vontade de se criar uma comunidade de pessoas engajadas com produções textuais, é fundamental que haja paixão pelo que se lê.

A especificidade da literatura é que ela pertence às artes; através da palavra, a literatura desdobra o mais profundo da constituição humana, que se apresenta no mundo de diversas formas. Na criação literária, há uma relação especial entre o leitor e o texto. 0 ficcionista, através da linguagem e da trama narrativa, apresenta muito de si mesmo e compartilha suas crenças no texto; quem o lê se vê envolvido e confrontado com a realidade e 
com a própria identidade. A literatura oferece outros modos de ver, compreender e transitar o mundo. Sem a ficção, o deslocamento imaginário seria impossível, não poderíamos ser transportados para outros lugares e nem experienciar vivências diferentes das que estamos acostumados. Essas repercussões internas resultantes da leitura literária são cabíveis para transformar o ser humano, levando-o à empatia. Yolanda Reyes, em “Ler e brincar, tecer e cantar: literatura, escrita e educação", apresenta o argumento de que, através da literatura, o mundo pode ser "mais habitável, pois o fato de nos vermos em perspectiva e de olharmos para dentro contribui para que se abram novas portas para a sensibilidade e para o entendimento de nós mesmos e dos outros" (2012, p.28).

A ficção é de igual forma um espaço de encontro, onde ocorre uma identificação com os enredos e/ou personagens descritos na obra. No entanto, para que haja essa troca, não há como contornar o comprometimento com a criação textual, pois é a atenção aos detalhes e o engajamento com o ambiente ficcional que possibilita o mergulho literário no mar de descobertas. Alberto Manguel (2017) em "O leitor como metáfora: o viajante, a torre e a traça" nos apresenta três tipos de leitor. 0 primeiro é aquele que dá permissão para que as palavras o transportem para novos ambientes; ele também aceita que sua compreensão de mundo pode ser desafiada e, ao fim da leitura, talvez não será a mesma. Manguel ainda diz que conscientes

de superar as limitações da geografia física e do tempo histórico, os leitores permitem o surgimento de uma outra geografia e de uma outra história à medida que avançam texto adentro, um espaço e um tempo que pertencem à narrativa textual e são reencenados diante dos olhos do leitor. (p. 37)

Assim, o leitor viajante vê na leitura um modo de reconhecer o mundo e de transcender o tempo e o espaço que Ihe são comuns. A segunda metáfora utiliza a torre para falar do leitor solitário; porém, ele enxerga a solidão como um privilégio, fechando-se em si mesmo e dificultando que outras pessoas o acessem na torre. A última categoria retrata aqueles que leem com pressa, devorando as páginas como uma traça; Manguel alerta que o leitor frenético corre o risco de engulir as palavras vorazmente, porém sem extrair conhecimento delas.

Através do Leitura Clandestina, o desejo dos idealizadores era de que os leitores nas escolas se sentissem convidados a viajar pelos contos de Clarice Lispector, mas que entendessem o valor da partilha e da leitura como um mergulho intenso, encontrando na escola um espaço para construir impressões aprofundadas sobre os textos lidos, sem que a opinião deles fosse desprezada. Além disso, Leitura Clandestina quis abrir o apetite literário dos jovens, pois acredita que muitas narrativas de Lispector têm os elementos necessários para tal, assim como falam de experiências que um adolescente pode julgar reconhecíveis na sua vida. E, na esteira do que foi estabelecido por Manguel, o projeto buscou mediar a formação de uma comunidade de leitores que entende que ler com entusiasmo não necessariamente significa ler como uma traça e que, enquanto se lê, o leitor deve estar atento aos pequenos detalhes narrativos, para melhor apreciar o texto.

$\mathrm{Na}$ introdução deste artigo, mostramos como a leitura é, muito seguidamente, percebida como atividade passiva na escola. Através das ações propostas pelo projeto de extensão, o grupo quis permitir que o leitor se tornasse também um autor indireto, tirando-o da inércia em relação ao livro. Para Bajour (2012), essa mudança de atitude acontece quando o leitor deixa-se levar pelo texto e passa a agir sobre ele, ainda que só no campo do pensamento. Acompanhando a linha do escritor, o leitor cria significações junto com ele, compartilhando um universo íntimo com o texto. Assim, há uma conversa entre leitor e obra, quer silenciosa, quer não. Bajour diz que "no balanço entre o dizer e o calar geralmente predomina o silêncio como refúgio" (p.20). Acreditamos que a obra 
da autora homenageada no projeto convida o leitor para o silêncio, pois ela mobiliza temáticas profundamente íntimas do humano, empregando uma linguagem poética e singular. No entanto, tomamos como norte o apontamento da autora argentina e oferecemos, no projeto, uma possibilidade de ação sobre o texto literário, seja através da escrita, da vocalização ou outras formas que o corpo encontra para expressar o poético.

\section{MATERIAIS E MÉTODOS}

Para cumprir com seus objetivos, o projeto Leitura Clandestina fez um estudo de obras de Clarice Lispector, na intenção de compor uma seleção vasta de contos e crônicas da autora, todos com temáticas que pudessem ser do interesse de adolescentes e, também, crianças e que os convidassem a olhar para o mundo com um outro olhar. Após realizar uma leitura cuidadosa, a seleção final contou com 28 textos de Lispector, que foram organizados em um arquivo e enviados para todos os professores que aderiram ao projeto e ficaram responsáveis por compartilhar o material com os estudantes.

Os contos e crônicas selecionados, na sequência de aparecimento na coletânea enviada aos professores e professoras cúmplices, foram: '0 Triunfo' - primeira colaboração de Clarice Lispector para a imprensa, publicado em 1940 na Revista Pan; 'A fuga' - do livro A Bela e a Fera, livro póstumo de 1979, que reúne seis textos do período de 1940-1941 e dois de 1977; 'Amor', 'Uma galinha' e ‘Mistério em São Cristóvão' - da obra Laços de família, de 1960; 'A repartição dos pães', 'Macacos', 'Tentação', ‘A quinta história' e ‘Uma amizade sincera' - do livro A legião estrangeira, de 1964; 'Felicidade clandestina', 'Restos de carnaval', 'Come, meu filho', 'Perdoando Deus', 'Cem anos de perdão', ‘Uma esperança', 'Uma histórias de tanto amor'; 'As águas do mundo'; 'Duas histórias a meu modo' e 'O primeiro beijo', da obra Felicidade Clandestina, livro de 1971 que trouxe contos inéditos e juntamente com a republicação de doze dos treze contos de A legião estrangeira; 'Tanta mansidão' e 'Tempestade de almas', da obra Onde estivestes à noite, do ano de 1974 e, finalmente, 'Explicação', 'Via crucis', 'Por enquanto', ‘Dia após dia', ‘Ruído de passos' e ‘Melhor que arder', da obra A via crucis do corpo, publicado em 1974.

O critério para convidar docentes foi o de proximidade com a coordenadora ou com os integrantes do projeto; também buscamos convidar profissionais que teriam uma identificação com a obra de Clarice Lispector, pois tal fato tornaria o projeto mais prazeroso para o docente, diminuindo a possibilidade de ele precisar dedicar muitas horas para a iniciativa fora do período dedicado às aulas, fossem elas remotas síncronas ou assíncronas.

De acordo com o preceito de que a extensão universitária deva promover interação entre a universidade e a comunidade na qual está inserida, buscamos desenvolver habilidades educativas junto ao corpo discente, assim como perceber o engajamento e a dinâmica de participação de mestres e alunos enquanto cenário possível para a retroalimentação de conhecimentos a fundamentar nossa formação para a docência, indagando-nos, constantemente, acerca das suas necessidades, anseios, aspirações e aprendendo com as motivações por eles expostas.

O projeto se desenvolveu em parceria com escolas públicas e privadas das cidades de Rio Pardo, Santa Cruz do Sul, Candelária e Taquari, tendo como público-alvo alunos do Ensino Fundamental II e Ensino Médio. Através de convites enviados via e-mail, solicitamos o engajamento dos professores de Língua Portuguesa e Literatura para incentivar e encorajar seus alunos que se sentissem à vontade para gravarem vídeos ou produções 
artísticas relacionadas com as obras literárias já pré-selecionadas pela equipe técnica, que as disponibilizou em anexo em formato PDF. Esses arquivos foram também divulgados no perfil do projeto no Instagram. Os alunos do curso de Letras, da disciplina de Diálogo Educacional Comunitário: Leituras de Diferentes Gêneros e Linguagens, professores do curso de Letras, professores das escolas convidadas e amigos convidados também puderam contribuir com o projeto, produzindo suas criações.

Para que houvesse um registro dos participantes, criamos um formulário online para acolher contato de usuários da plataforma dispostos a integrar a ação, sempre com os termos de consentimento para uso da imagem e da voz. 0 formulário contava com duas modalidades de preenchimento: uma feita pelo próprio aluno, quando esse fosse maior de 18 anos, e outra assinada pelos pais ou responsáveis, quando o estudante fosse menor de idade; os professores preencheram a primeira modalidade também, por serem adultos. A escolha desses meios deve-se à atual situação de pandemia, que impossibilita o contato e aglomerações que outrora seriam utilizadas para materializar o projeto. Dois integrantes do grupo ficaram responsáveis por averiguar as respostas do formulário online, comparando os dados com os materiais recebidos para que nenhuma produção fosse divulgada sem a autorização do participante.

Em relação à forma como o projeto foi concretizado nas salas de aula remotas, os integrantes do Leitura Clandestina em momento algum impuseram uma única maneira de utilização do material disponibilizado, nem mesmo sugeriram qual seria a melhor metodologia ou abordagem; pelo contrário, houve um diálogo aberto com os docentes participantes, no intuito de deixá-los confortáveis para comporem a ideia do projeto da maneira que achassem mais interessante. A partir dessa perspectiva, conhecendo sua turma, o docente teve a liberdade de selecionar um número menor de contos dentre os 28 , se assim quisesse ou também poderia escolher somente um e usá-lo em diversas atividades, como aconteceu com algumas das turmas de crianças.

A partir da leitura e interpretação dos textos, foi proposto que os professores e os estudantes produzissem uma manifestação poética, seja através da leitura em voz alta, de um desenho, de uma produção escrita, de uma performance, enfim, desejamos viabilizar infinitas possibilidades de manifestações criativas dos participantes. Julgamos ser importante essa resposta artística, pois, assim, o leitor passa a ser mais ativo e pode traduzir em outra dimensão da linguagem suas impressões sobre a narrativa. Essa proposta foi pensada a partir do conhecimento de que há pouco espaço, nas aulas de Literatura ou Língua Portuguesa, para a produção em linguagem, ação que pode ser muito benéfica para os estudantes que colocam o corpo em movimento para expressarem algo abstrato, o pensamento.

Para a divulgação da homenagem à Clarice Lispector, foi utilizada a rede social Instagram como ferramenta de socialização e realização da atividade, aberta ao público e de forma gratuita. A escolha deveu-se à atual situação de pandemia, que impossibilita o contato e aglomerações que seriam necessárias para o desenvolvimento presencial do projeto. Com o desígnio de divulgar e apreciar as obras produzidas por Clarice Lispector, tanto na Literatura quanto nas artes plásticas, foi considerado seu centenário, comemorado em 10 de dezembro de 2020. A plataforma, através do perfil <https://www.instagram.com/leitura.clandestina/>, também foi escolhida por proporcionar uma horizontalização de produções. 


\section{RESULTADOS E DISCUSSÃO}

0 projeto Leitura Clandestina, ao longo de 5 meses, teve 115 participantes, estudantes em sua grande maioria. Escolas públicas e privadas das cidades de Rio Pardo, Santa Cruz do Sul, Candelária e Taquari aceitaram o convite e, através de alguns de seus docentes, mobilizaram alunos com o espaço do Leitura Clandestina no meio virtual. Dessa forma, não só nosso objetivo principal - de homenagear o centenário de Clarice Lispector foi atingido, mas também os secundários, visto que tivemos um número significativo de participações e envios de produções diferenciadas (vídeos, desenhos, depoimentos, textos escritos, entre outros) envolvendo várias faixas etárias. E, em meio ao primeiro ano pandêmico, conseguimos nos fazer presentes através de uma proposta extensionista na ressignificação da vida de inúmeros jovens, crianças e adultos que tiveram, em alguns casos, seus primeiros contatos com as obras da autora.

Consideramos que o diálogo aberto com os docentes participantes foi, ao mesmo tempo, mola propulsora e resultado, pois nada acontece quando os envolvidos sentem-se desconfortáveis para agir e explorar as múltiplas facetas que a leitura proporciona. A coragem que tivemos de fugir do ordenamento funcional e utilitário que, infelizmente, recai sobre as práticas de mediação de leitura na escola alavancou manifestações íntimas e verdadeiras.

Os inscritos tinham liberdade para criar o que desejassem a partir das leituras enviadas, sendo amparados, quando alunos da educação básica, por seus professores de Língua Portuguesa ou de Literatura. Organizados em grupos de afinidade ou trabalhando sozinhos, essas 115 pessoas retornaram 56 produções, todas singulares e que se mantém disponíveis no perfil já referido. Apenas dois grupos plagiaram conteúdo da internet e, por isso, não foram postados na página, que já tem 44 posts baseados no material recebido, além de outros sobre a vida de Clarice Lispector e outros escritores próximos à autora. Houve também participações de alunos e professores do curso de Letras, professores das escolas parceiras e amigos que, convidados, também empenharam seu corpo, sua voz ou outra dimensão criativa da linguagem para compartilhar sua experiência leitora com e através da poética de Clarice Lispector.

Com isso, confirmamos, como esperávamos, que os textos da autora não são inacessíveis ou difíceis para crianças e jovens. Contabilizamos o empenho desses participantes como resultado positivo da ação do projeto, que ressignificou a leitura enquanto oportunidade de partilha e de escuta na escola e fora dela. Distante de tantas manifestações excessivamente escolarizadas de compreensão da leitura literária, o Leitura Clandestina gestou outra inserção da literatura na vida dos estudantes, mais rica, menos passiva, sendo, todos eles, também autores indiretos que exerceram a audácia de experimentar escutar seus corpos em voz. (BAJOUR, 2012).

Em termos de formação para a docência, o projeto Leitura Clandestina, concebido enquanto curricularização da extensão acadêmica, foi essencial para que pudéssemos reconhecer, como futuros professores, que os saberes não são constituídos apenas enquanto conhecimento. A dimensão educativa do espaço escolar ressignifica-se o tempo todo, pois tem a ver com entender o modo como podemos compartilhar a vida que nos é dada viver. Isso ficou evidente no período pandêmico, quando não apenas a instrução técnica tinha relevância. Ela, a técnica, nos ajudou a alavancar conhecimentos que nos impulsionassem na direção de superar as mazelas do distanciamento. Contudo, exercer a pedagogia, uma ciência da prática, significa muito mais, envolve ter a coragem de aceitar que, quando se trata de gente, teremos de sempre agir através da linguagem, 
recurso que nos possibilita, entendendo e assumindo o que somos, caminhar na direção de sempre novas outras pessoas. Essa ação tem a ver com a leitura, pois

carecemos de interpretar o que nos acontece e decidir como queremos acontecer junto aos demais. Este texto do qual somos personagens é a própria vida. [ ...] Portanto, ao ler um texto nos livros, um quadro nas paredes de um museu ou uma pintura na empena de um edifício nas avenidas urbanas, estamos em exercício de entendimento do mundo, em um ensaio do pensamento que nos provoca o recôndito, as entrelinhas ocultas que o noticiário e a ideologia nos negam para manipular-nos. (YUNES, 2021, p. 2)

Assumir que a tarefa de um professor é a de ser um mediador associa-se à compreensão de um ofício que tem a especificidade de ocupar um entre lugar, que, como aponta Yunes (2021) "é a ponte levadiça que se estende do castelo interior de cada um em direção ao outro, este desconhecido que, no entanto, garante que eu possa ter ideia de quem sou". (p. 1) A formação em uma licenciatura, constantemente, nos remete à reflexão acerca do exercício do aprender. Na universidade, enquanto alunos, compreendemos que as experiências vividas na escola têm papel fundamental na nossa constituição, tanto em termos do aprofundamento de nosso pensamento crítico e reflexivo, quanto na validação de nossa sensibilidade. A extensão universitária é campo profícuo para aflorar tal compreensão.

Inevitavelmente, tivemos a preocupação de se nossa ideia seria bem aceita pelos alunos, professores e convidados, ainda mais pela sensibilidade que a situação mundial tem nos impingido diariamente. A forma que uma obra nos envolve, poderia ser comprometida pela falta de proximidade. Ana Elisa Ribeiro (2020) exemplifica esse sentimento e dúvidas que foram surgindo e como isso foi se definindo com o decorrer do andamento do projeto:

\begin{abstract}
Tirar melhor proveito do tempo presente pode ter sido necessário, uma escolha diligente, embora tenha sido também o único modo de fazer, já que o passado estava encerrado, em muitos sentidos, e o futuro ainda nos parecia e parece opaco. $\mathrm{Na}$ escassez dos encontros "presenciais", foi preciso repensar os aproveitamentos dos encontros "não presenciais", algo que pode parecer paradoxal para muitos e muitas colegas, mas que se desvelou em nossas práticas de "ensino remoto". É possível a presença sem o corpo? É possível aprender sem estar presente em espaço físico coincidente? Onde está nossa atenção é onde estamos? Se vamos nos encontrar pouco no nó tempo-espaço simultâneos, o que fazer durante esses momentos? Perdê-los com a fala monologal? Há uma conexão que de fato nos aproxima na distância? Copresença é algo que depende muito mais dos tempos coincidentes do que dos espaços? 0 que é a ausência no presencial e no remoto? (p. 147)
\end{abstract}

A tentativa de apreender a intensidade desses questionamentos, nos conduziu a outro resultado benéfico: o de termos nos aventurado na curadoria de textos. Como já mencionado em páginas anteriores, realizamos leitura e seleção de contos e crônicas de Clarice Lispector em diferentes obras da autora, buscando aqueles que, em nosso entendimento naquele momento, poderiam conter os elementos necessários para aguçar o paladar para a leitura de Clarice por abordarem aspectos da vida reconhecíveis como substanciais pelos jovens.

Tornamo-nos curadores de 28 textos que, quando abordados no ambiente escolar, pudessem garantir aos professores a liberdade de definir seus planos de ação; a leitura do arquivo poderia ser oferecida aos jovens integralmente ou passar pelo filtro da escolha do docente, que foi o caso das turmas de $6^{\circ}$ ano das escolas de Rio Pardo. Da mesma forma, quisemos que a criação discente fosse livre, podendo ser mediada pelo professor, caso o estudante enfrentasse dificuldade. No entanto, sempre mantivemos firme a posição de que ninguém deveria participar do projeto de maneira forçada, pois tal ato minaria o caráter poético da produção. Outra regra essencial era a de que os inscritos jamais fizessem algo que os deixasse desconfortáveis; por essa razão as 
possibilidades de ações poéticas são ilimitadas pelo projeto, já que, ao listar alguns tipos de produção, poderíamos estar inibindo o agir em linguagem de alguém ou deixando de lado ideias dos próprios participantes.

A natureza das produções foi poética e plural. Contudo, a escolha maior pelos contos "Tentação" e "Come, meu filho" saltam aos olhos: o primeiro narra o encontro de uma menina com um cachorro, ambos ruivos, e teve ocorrências mais frequentes entre alunos adolescentes; o segundo trata-se de uma conversa entre mãe e filho pequeno, e sua seleção aconteceu entre alunos do $6^{\circ}$ ano, mediada pelos professores. É interessante a percepção de que as temáticas parecem influenciar muito nas decisões de qual conto será interpretado de maneira material, ou seja, através de uma ação que materializa a interpretação. A preferência pelos contos citados nos levou a interpretá-la não só enquanto marca de manifestação da subjetividade, integrante de toda a interpretação literária, mas também como possibilidade de que, talvez, os participantes tenham neles encontrado abertura para a linguagem do imaginário, aquela que os fez adentrar no existencialismo do fabuloso, integrando corpo e alma. Com Bachelard (1988) é possível afirmar que a força poética que irrompe da imagem potencializa o devaneio que nos leva a substituir "diante do mundo a percepção pela admiração. Admirar para receber os valores daquilo que se percebe." (BACHELARD, 1988, p. 113).

Até mesmo para acadêmicos de Letras, como recebemos o relato, foi muito diferente a experiência de ouvir a sua própria leitura vocalizada através de um vídeo, bem como os estudantes das escolas demonstravam ansiedade aguardando pelos dias de publicação do perfil no Instagram para visualizarem suas produções divulgadas para o público.

Essa jornada que os leitores fizeram entre primeiros contatos, obra, escritora e produção poética, bem como o impacto pela vocalização, são ímpares e muito marcantes. Da mesma forma como foram enriquecedores os caminhos possibilitados pelo Leitura Clandestina no rumo de nossa formação.

\section{CONCLUSÃO}

Leitura Clandestina pôde reacender a chama da literatura em muitas pessoas, tanto professores como estudantes, provando que a arte da palavra é poderosa para tocar o mais profundo do ser e assim transformá-lo. Tivemos o privilégio de oferecer um espaço de acolhimento para pessoas que deixaram Clarice Lispector Ihes tocar e vibraram juntos. Contemplando diversos interesses, áreas de estudos e objetivos, alcançamos um público de diferentes idades e vivências, que se permitiram experenciar a potência artística do corpo, voz e papel.

A criação do projeto Leitura Clandestina foi uma ação diretamente ligada aos estudos da fenomenologia e vocalidade, pois criou meios de colocar os estudantes da região em um estado de reflexão e ação sobre suas experiências individuais de leitura. 0 resultado foi uma pluralidade de imagens poéticas, pois a experiência leitora também é individual. As percepções, por mais que todos as tenham, foram diferentes entre si, carregadas do que Ihes foi ensinado, experiências e reflexões singulares.

Para além do impacto regional, que muito nos emocionou e provou, mais uma vez, a importância de viver em linguagem e deixá-la ser em nós, o projeto teve a honra de ser incluído em uma Cátedra da UNESCO em Leitura, o ReLer (Rede de Estudos Avançados em Leitura da PUC-Rio), garantindo, assim, visibilidade nacional para o projeto. Tal inclusão evidencia que a literatura é, realmente, resistência ao modo de viver contemporâneo, sem tempo para contemplação de si mesmo e do outro; a literatura, a linguagem poética, é um espaço de 
transformação e, ao transformar alguém, pode também mudar um coletivo e alcançar o inalcançável. Outro reconhecimento importante do Leitura Clandestina foi a premiação Destaque no eixo de Extensão da Mostra de Ensino, Extensão e Tecnologia da UNISC de 2020.

Assim, comprovamos a ideia de que o simples (e não o simplificado) ainda é capaz de sensibilizar pessoas, inclusive crianças e jovens, mesmo em um momento difícil e delicado. A literatura tem a capacidade de acolher e abrigar com as palavras, que é o que muitos leitores procuram quando escolhem uma obra. Tornar possível o contato entre alunos e Clarice Lispector foi o nosso maior desejo, e acreditamos que alcançamos esse objetivo com sucesso.

\section{AGRADECIMENTOS}

Agradecemos nossa professora Ângela Cogo Fronckowiak, por ser a luz desse projeto. Agradecemos aos nossos colegas de curso, Cássio, Daniela, Maria Cristina e Sara, que sonharam junto conosco cada momento do Leitura Clandestina. Agradecemos, também, os professores, alunos e convidados que participaram do projeto, contribuindo de forma riquíssima para que ele se tornasse o que foi e é, já que as publicações ainda podem ser acessadas através do perfil do Instagram citado anteriormente.

\section{REFERÊNCIAS}

BACHELARD, Gaston. A poética do devaneio. Tradução Antônio de Pádua Danesi. São Paulo: Martins Fontes, 1988.

BAJOUR, Cecília. Ouvir nas entrelinhas: o valor da escuta nas práticas de leitura. Tradução de Alexandre Morales. São Paulo: Pulo do Gato, 2012.

BICUDO, M.A.V. Pesquisa Qualitativa; Significados e a Razão que a Sustenta. Revista Pesquisa Qualitativa, São Paulo, Ano 1, n.1, 2005, p. 7-26.

BONDÍA, J. L. Notas sobre a experiência e o saber de experiência. Revista brasileira de educação, v. 19,p. 20-28, 2002.

LISPECTOR, Clarice. 0 Triunfo. Revista Pan, Rio de Janeiro, Ano VI, n. 227, mai. 1940. Disponível em: <https://ims.com.br/por-dentro-acervos/triunfo-a-estreia-de-clarice-na-imprensa/>. Acesso em: $6 \mathrm{dez.} 2021$.

LISPECTOR, Clarice. [1960] Laços de família. 12. ed. São Paulo: José Olympio, 1982.

LISPECTOR, Clarice. [1964] A legião estrangeira. São Paulo: Ática, 1977. (Coleção Nosso Tempo)

LISPECTOR, Clarice. [1971] Felicidade Clandestina: contos. 2. ed. Rio de Janeiro: José Olympio, 1975.

LISPECTOR, Clarice. [1974] Onde estivestes à noite. 3. ed. Rio de Janeiro: Nova Fronteira, 1980.

LISPECTOR, Clarice. [1974] A via crucis do corpo. Rio de Janeiro: Artenova, 1974.

LISPECTOR, Clarice. [1979] A Bela e a Fera. Rio de Janeiro: Rocco, 1999.

MANGUEL, Alberto. O leitor como metáfora: o viajante, a torre e a traça. Tradução de José Geraldo Couto. São Paulo: Edições Sesc São Paulo, 2017. 
REYES, Yolanda. Ler e brincar, tecer e cantar: literatura, escrita e educação. São Paulo: Pulo do Gato, 2012.

RIBEIRO, Ana Elisa. Ensino, pesquisa e extensão na pandemia: dor e delícia dos letramentos digitais. In: ASSIS, Juliana Alves; KOMESU, Fabiana; FLUCKIGER, Cédric (organizadores). Práticas discursivas em letramento acadêmico, Belo Horizonte: Editora PUC Minas, 2020, p. 144-178.

SOARES, Magda. A escolarização da literatura infantil e juvenil. In: EVANGELISTA, Aracy Alves Martins; BRANDÃO, Heliana Maria Brina; MACHADO, Maria Zélia Versiani (organizadoras). Escolarização da leitura literária. $2^{\mathrm{a}}$ ed., $3^{\mathrm{a}}$ reimp. Belo Horizonte: Autêntica, 2011, p. 17-48.

YUNES, Eliana. Mediadores e leitura. Especialização em Literatura Infantil e Juvenil. Caxias do Sul: Instituto Quindim - Universidade de Caxias do Sul, 2021. Disponível em:

<https://www.institutoquindim.com.br/post/mediadores-e-leitura-por-eliana-yunes>. Acesso em: 23 out. 2021. 